\title{
A Políica Nacional de Humanização como política que se faz no processo de trabalho em saúde
}

Serafim Barbosa Santos Filho' Maria Elizabeth Barros de Barros ${ }^{2}$ Rafael da Silveira Gomes ${ }^{3}$

SANTOS FILHO, S.B.; BARROS, M.E.B.; GOMES, R.S. The National Humanization Policy as a policy produced within the healthcare labor process. Interface - Comunic., Saude, Educ., v.13, supl.1, p.603-13, 2009.

This paper had the aim of conducting an analytical exercise about how the National Humanization Policy is undertaken, with regard to the institutional support function, based on different mechanisms, guidelines and principles. The text is divided into three parts. The first part provides reflections concerning the concepts of humaneness and humanism on which the analyses are based. The second seeks to expand the debate regarding the indissociability of healthcare and management and the way of providing institutional support. The third covers the indissociability between the production of services and the production of subjects and moves the discussion on these three parts forward for them to be developed in other planes of analysis. Throughout the text, emphasis is placed on banking on including different subjects and on analysis and collective management of labor processes as a strategy for creating productive destabilization and humanization practices within the healthcare services.

Keywords: Humanization of assistance. Institutional support. Co-management. Collective labor process analysis. Public policies.
Este artigo tem como objetivo realizar um exercício analítico do modo de fazer da Política Nacional de Humanização (PNH) sobre a função apoio institucional, com base em diferentes dispositivos, diretrizes e princípios. O texto está dividido em três partes: na primeira, traz reflexões acerca da concepção de humano e humanismo que fundamenta as análises; a segunda busca ampliar o debate sobre a indissociabilidade entre atenção e gestão e o modo de fazer apoio institucional; a terceira aborda a indissociabilidade entre a produção de serviços e produção de sujeitos, e encaminha a discussão dessas três partes que se desdobram em outros planos de análise. Ressalta, em todo o texto, a aposta na inclusão dos diferentes sujeitos e na análise e gestão coletiva dos processos de trabalho como estratégia para criar desestabilizações produtivas e práticas de humanização dos serviços de Saúde.

Palavras-chave: Humanização da assistência. Apoio institucional. Cogestão. Análise coletiva dos processos de trabalho. Políticas públicas.
${ }^{1}$ Ministério da Saúde, Política Nacional de Humanização (MS/PNH). Rua Gonçalves Dias, 60/901, Lourdes, Belo Horizonte, MG, Brasil. 30.140-090 serafimsantos@terra.com.br 2 Departamento de Psicologia, Universidade Federal do Espírito Santo. ${ }^{3} \mathrm{MS} / \mathrm{PNH}$. 


\section{Introdução}

O presente artigo nasce de reflexões pautadas em experiências concretas que temos vivenciado como consultores da Política Nacional de Humanização (PNH) e como trabalhadores do campo da formação de profissionais de saúde. As questões e discussões que iremos abarcar no texto emergiram e são atravessadas por essas práticas, pelas nossas ações de apoio institucional ${ }^{4}$ e pelas experiências de formação que temos desenvolvido tanto no âmbito dessa política como fora dela. Neste artigo nos propomos a articular os referenciais da PNH com alguns aspectos dos processos de trabalho em saúde, perspectivando sua análise a partir de um diálogo com a proposta metodológica dessa Política. Buscamos pensar, portanto, questões sobre a contribuição da $\mathrm{PNH}$, no que tange à discussão dos processos de trabalho e da organização de serviços de saúde.

A PNH coloca-se como uma "política" que se constitui com base em um conjunto de princípios e diretrizes que operam por meio de dispositivos ${ }^{5}$ (Brasil, 2006, 2004). Por princípio, entendemos o que impulsiona ações, disparando movimentos no plano das políticas públicas. No caso da $\mathrm{PNH}$, o movimento a que se propõe é o da mudança dos modelos de atenção e gestão fundados na racionalidade biomédica (fragmentados, hierarquizados, centrados na doença e no atendimento hospitalar). Ela se afirma como política pública de saúde com base nos seguintes princípios: a inseparabilidade entre clínica e política, o que implica a inseparabilidade entre atenção e gestão dos processos de produção de saúde; e a transversalidade, entendida como aumento do grau de abertura comunicacional nos grupos e entre os grupos, isto é, a ampliação das formas de conexão intra e intergrupos, promovendo mudanças nas práticas de saúde (Passos, 2006).

As diretrizes da PNH são suas orientações gerais e se expressam no método da inclusão de usuários, trabalhadores e gestores na gestão dos serviços de saúde, por meio de práticas como: a clínica ampliada, a cogestão dos serviços, a valorização do trabalho, o acolhimento, a defesa dos direitos do usuário, entre outras. Os dispositivos, por sua vez, atualizam essas diretrizes por meio de estratégias construídas nos coletivos concretos destinadas à promoção de mudanças nos modelos de atenção e de gestão em curso, sempre que tais modelos estiverem na contramão do que preconiza o SUS. Entre os dispositivos propostos pela $\mathrm{PNH}$, estão: acolhimento com classificação de risco, colegiado gestor, visita aberta e direito a acompanhante, equipe transdisciplinar de referência, Programa de Formação em Saúde e Trabalho (PFST), projetos cogeridos de ambiência. A implantação desses dispositivos se efetiva caso a caso, considerando-se a especificidade dos serviços, partindo sempre da análise dos processos de trabalho, processos que nunca se repetem. A PNH traz, em seu escopo, a articulação de um conjunto de referenciais e instrumentos, operando com eles para disparar processos.

Em alguma medida, a contribuição da PNH assume, em nosso entendimento, um caráter singular, haja vista que sua finalidade tem sido alterar a maneira de trabalhar e de interferir nos processos de trabalho no campo da Saúde. Com esse objetivo, uma das direções de abordagem da PNH materializada nos/e com os serviços é a criação de formas de trabalho que não se submetam à lógica dos modos de funcionamento instituídos. Formas de trabalhar que superem as dissociações entre os que pensam e os que fazem, entre os que planejam e os que executam, entre os que geram e os que cuidam. Parte-se do entendimento do trabalho como atividade situada, como espaço coletivo de produção de saberes, de negociação e gestão (Schwartz, Durrive, 2007). Associada a essa premissa, impõe-se, então, a necessidade de uma reflexão sobre os usos do que tem sido nomeado como princípios e diretrizes dessa Política.
${ }^{4}$ A noção de apoio institucional será desenvolvida ao longo do texto.

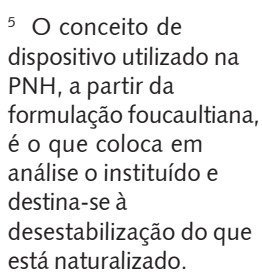


Neste artigo, afirmamos a PNH como aporte e articulação de um conjunto de referenciais e de instrumentos, que tem como finalidade maior estar em meio aos processos de trabalho, no movimento de sua constituição, buscando ajudar a desequilibrar seus arranjos e produzir desvios nas relações instituídas, instigando novas composições, outras possibilidades de ser e trabalhar no âmbito da Saúde. O que importa, nessa direção analítica dos processos de trabalho, inseparável de uma perspectiva de intervenção, é potencializar outros modos de trabalhar que emergem cotidianamente nos serviços, partindo do que ali é experimentado pelo trabalhador.

O enfrentamento do que está instituído acontece constantemente pela invenção de outras formas de agir nos espaços de trabalho, pela produção incessante de saberes realizada na atividade laboral, porém, muitas vezes, esse enfrentamento é invisibilizado ou enfraquecido. Colocar os processos de trabalho em análise, dessa maneira, não se dissocia de uma perspectiva de intervenção, na medida em que fomenta e potencializa movimentos, desvios e rupturas, que sugerem transformar os modos de trabalhar e de ser no trabalho. Os processos de trabalho são processos de produção de sujeitos, uma vez que homem e mundo não são realidades já dadas, constituídas a priori, logo o processo de trabalho é processo de constituição de sujeitos. De acordo com essa premissa é que fazemos um convite à reflexão sobre os usos dos dispositivos da $\mathrm{PNH}$.

O que pode a PNH? Qual sua potência disruptora? Que forças de naturalização podem nos fazer sucumbir ao "deve ser assim"? Tais interrogações nos forçam a pensar sobre o que tem sido feito ao se atualizarem os princípios e diretrizes da referida Política no cotidiano dos serviços de saúde. Com esse objetivo, o texto será dividido em alguns subitens. Neles, apresentamos reflexões acerca da concepção de humano e humanismo, que fundamentam nossas análises e ações, a partir do que tem sido formulado pela PNH. Buscamos, também, ampliar o debate sobre a indissociabilidade entre atenção e gestão e o modo de fazer apoio institucional no âmbito da PNH. Focalizamos, ainda, a indissociabilidade entre produção de serviços e produção de sujeitos, e encaminhamos a discussão desses aspectos que se desdobram em outros planos de análise, apresentando um modo de intervir e de fazer apoio institucional, dialogando com referenciais que selecionamos para esta discussão.

Entre os referenciais que permeiam a discussão, estão: as concepções trazidas por Campos (2006, $2003,2000,1998$, 1997) para o campo da Gestão em Saúde, bem como algumas produções efetivadas no âmbito da PNH por Benevides e Passos (2005), Barros, Mori e Bastos (2006), Brasil (2006), Heckert e Neves (2007), Barros e Santos Filho (2007), Campos (2007) e Santos Filho (2008).

\section{O conceito de humano: um outro humanismo comparece...}

A PNH indica uma concepção de homem que se constitui no concreto das experiências, nas lutas cotidianas e em uma direção ético-política em que se opõe "o homem" a "um homem", a todos nós, procurando resistir ao que se concebe como "homem ideal". Assim, a concepção de humano com a qual trabalha subverte "o homem" como abstração, modelo ou idealidade a partir do qual se ajusta a existência humana (Benevides, Passos, 2005). Trata-se, portanto, de uma concepção de humano que parte das formas de ser que se constituem no concreto das experiências dos serviços. Uma forma de ser humano que não está dada desde sempre ou que se define a partir de um modelo geral de humanidade. Por conseguinte, não parte de um entendimento da humanização como um processo que objetiva aproximar os diferentes sujeitos desse ideal, do homem-padrão.

A humanização, tal como nos indica a PNH, efetiva-se nas práticas em saúde a partir delas, ou seja, das formas como agimos no cotidiano dos serviços. Está voltada para homens e mulheres comuns que compõem o SUS, em suas experiências, com os trabalhadores e usuários que habitam e produzem o dia-a- dia dos serviços de saúde. É no encontro entre estes sujeitos concretos, situados, que a política de humanização se constrói.

Partindo desse referencial, toma-se como princípio do trabalho nos serviços um enfoque que contribui para desidealizar a concepção de humano e de humanismo, assim como de "serviços idealizados". Nesse caso, o objetivo não se confundiria com um objetivo geral de mudar o serviço e, sim, de viabilizar a compreensão de como se institui um serviço e um processo de trabalho em saúde. Um serviço e um processo, sempre conduzidos por "humanos", sujeitos em constante processo de 
diferenciação, de produção de novos modos de existência, processos que desestabilizam formas instituídas de ser trabalhador e experimentam outras. Então, como tem se construído um modo de ser humano nos serviços de saúde? Certamente isso vai depender dos atributos com os quais se propõe compreender o humano e os processos de humanização.

Para a PNH, esse princípio se operacionaliza colocando-se em análise os serviços, vendo neles e com eles, com aqueles que o compõem e habitam nele, o que funda seus modos de constituição, seus diferentes modos de ser e de agir no SUS. Em nosso entendimento, a PNH não propõe um tipo de serviço específico, um SUS ideal, mas também não deseja qualquer tipo. Aposta em uma abordagem em que os coletivos do SUS são convocados para pôr em análise os diferentes serviços e as formas de agir neles. Com isso, destina-se à instituição de outras modalidades de agir em Saúde, que possuam, como uma aposta ético-política, a defesa da vida, apoiada em valores como a produção de autonomia e protagonismo dos sujeitos que constroem o SUS (Brasil, 2006).

No entanto, como fazer isso? Entendemos que esse processo tem se efetivado no âmbito da Política em pauta por meio de algumas estratégias: a) convocando todos aqueles que militam no SUS, num movimento de inclusão, para discutir o serviço (inclusão dos trabalhadores, gestores e usuários); b) incluindo variáveis que atravessam e constituem todo o serviço, todo o processo de trabalho local para análise do processo de trabalho, possibilitando a emergência do que seriam os vetores que produzem os modos de ser e fazer daquele serviço; c) ajudando a disparar esses movimentos e assumindo suas consequências, isto é, exercitando um apoio institucional (Campos, 2006, 2003) no sentido de intervenção-oferta para ajudar a ressignificar a compreensão do serviço e de suas bases de organização. Assim, a própria compreensão do que estamos considerando "intervenção", que se efetiva nas ações de apoio institucional, contribui para essa ressignificação.

O apoio institucional é uma estratégia metodológica para o enfrentamento dos inúmeros desafios que o trabalho no campo da Saúde nos coloca, uma vez que, como nos aponta Campos (2003, p.86), os trabalhadores em Saúde:

[...] lidam com o limite humano, com nossa impotência, com a evidência de que não somos deuses [...]. Lidam com a morte, a doença e a dor. Trabalham em ambientes perigosos (germes, fracassos, competição, etc.), logo, precisam, além de planos de carreira e salários, de Apoio, o que tem o sentido de estar sempre em análise. Trata-se de uma função que se expressa num determinado modo de fazer, que não está localizada numa pessoa e persegue a criação de grupalidade, de forma a fortalecer e montar redes de coletivos.

O apoio institucional, no sentido que lhe é atribuído na $\mathrm{PNH}$, instaura uma relação dinâmica entre o apoiador institucional e a equipe apoiada: nem uma postura de passividade ou omissão (dos apoiadores), nem de ações à revelia dos grupos ou de elaboração de pareceres, planos ou protocolos e normas para as equipes. Trata-se de um apoio à cogestão que destina-se a afirmar e a atiçar a produção de coletivos organizados. A função do apoiador institucional é de contribuir para a gestão e organização de processos de trabalho, na construção de espaços coletivos onde os grupos analisam, definem tarefas e elaboram projetos de intervenção.

Apoio, portanto, que envolve a discussão-problematização dos modos como a gestão nas relações de trabalho se expressa. Por conseguinte, esse trabalho de apoio se afirma com base em um pressuposto essencial: a recusa de qualquer forma de tutela. Apoiar, para PNH, é estar junto com os diferentes sujeitos que constituem os sistemas de saúde - gestores, usuários e trabalhadores - discutindo e analisando os processos de trabalho e intervindo nas formas como os serviços estão organizados, potencializando aqueles que trabalham e utilizam os serviços como protagonistas e corresponsáveis pela produção de saúde, combatendo qualquer relação de tutela ou deslegitimação do outro.

Em que medida se tem dado conta disso? Em que medida esse tipo de atuação tem viabilizado a qualidade da atenção aos usuários e a reorganização dos processos de trabalho na direção da gestão efetivamente partilhada? Aqui, certamente, não estamos procurando respostas. A construção de modos que afirmem os princípios do SUS na sua radicalidade precisa sustentar essas questões que buscam afirmar o aspecto constituinte do SUS. 


\section{No rastro da premissa de indissociabilidade entre atenção e gestão...}

Partindo do que a PNH adota como princípio, ou seja, a indissociabilidade entre atenção e gestão (Brasil, 2006), a proposta seria contribuir com o modo de discutir e construir, no coletivo, estratégias para melhorar o acesso e a qualidade dos serviços, entendidos como indissociáveis dos modos como esses são geridos. Nesse sentido, também, o objetivo da PNH não se confundiria com um objetivo de assegurar o acesso e a qualidade da atenção a partir de concepções e determinações externas aos serviços. Pelo contrário, teria como objetivo ajudar os coletivos organizados na produção e na articulação de arranjos, pactos e ações concretas, capazes de viabilizar mudanças na gestão, indispensáveis para que haja também mudanças nos modos de atenção (Campos, 2003).

E como se faz isso? Como se efetiva a operação desse princípio? As rodas de conversa, espaços coletivos que incluem os diferentes atores dos serviços, são um dos caminhos que se acredita potente para abrigar e ampliar essas discussões. No entanto, o que agregaria, de modo mais incisivo e especial, seria a intensidade e a qualidade do apoio institucional, que se efetiva em meio aos processos, que se concretiza ajudando a pôr em análise os processos de trabalho. Esse caminho proposto opõe-se e diferencia-se de estratégias baseadas na prescrição de regras para implantação de um dispositivo, o que é incompatível com a própria concepção de dispositivo com a qual trabalha a PNH. O caminho é a afirmação de uma perspectiva participativa que permitiria aos coletivos atribuírem sentidos, fazerem e sustentarem conexões no/e do processo de trabalho. Novamente ressaltaríamos o modo de estar, de operar, de atuar no "entre", de estar junto, de intervir... (Barros et al., 2007; Barros, Benevides, 2007; Barros, Mori, Bastos, 2006).

Não basta, portanto, ter como direção a "gestão participativa" dos serviços se essa diretriz se operacionaliza como prescrição verticalizada de modos de fazer ou de metas a serem alcançadas. Em muitas situações, deseja-se um produto e não se tem dado muita importância ao modo como ele se viabiliza. O processo de trabalho fica reduzido ao produto. As ações, no âmbito da $\mathrm{PNH}$, destacam a importância de se (re)organizarem os processos de trabalho para mudar a oferta de serviços, priorizando o modo de se discutir e articular essa (re)organização em equipe, o "que fazer" não pode suplantar o "como fazer".

O dispositivo do "Acolhimento com Classificação de Riscos" ilustra isso muito bem: o interesse institucional, o projeto, a meta e, às vezes, até os "decretos" pelos quais esse dispositivo tem sido implantado nos serviços, parece pressupor uma reorganização natural da equipe, para melhorar a atenção ao usuário, como se fosse intrínseco à proposta. Sem se dedicar atenção e estratégias para efetivar essa reorganização - como se fosse possível pensar o serviço fora da rede em que este se efetua, isolado das demais práticas de produção de saúde e independente dos que nele trabalham - o dispositivo se transforma em um instrumento a ser implantado, perdendo sua potência de transformação das práticas.

As reflexões levantadas até aqui nos levam a um outro cenário de questões sobre o exercício efetivo desse saber-fazer da PNH. Saber-fazer em construção e, por isso, mantendo-se aberto para interrogarse permanentemente: em que medida esse saber-fazer da PNH tem dado conta de sua proposta éticopolítico-metodológica? Em que medida esse tipo de atuação-intervenção, numa perspectiva avaliativa, tem sido capaz de fazer uma cobertura ampliada das ações e da qualidade da atenção como indicadores dos efeitos produzidos por essa intervenção? Em que medida se tem dado conta desse tipo de apoio? Fazendo um desdobramento das questões anteriores, diríamos que a proposta é atuar e ajudar os coletivos locais a se fortalecerem para protagonizar essas discussões e articular os componentes do processo de trabalho (arranjos, pactos, ações, dentre outros).

Chamamos a atenção para um aspecto: não se trata, na $\mathrm{PNH}$, de ocupar um ou outro polo extremo da discussão, nem se influenciar pelas pressões de resultados, nem pela idealização de um modo harmônico de trabalho, que se efetiva a partir de perspectivas abstratas, descoladas do que se vive efetivamente no dia-a-dia dos serviços. Trata-se do desafio de construir e ocupar o lugar de chamar para a análise, de pôr em análise o próprio trabalho, fazendo isso nos espaços coletivos onde é essencial a inclusão dos atores, trabalhadores, gestores e usuários. Conforme indicamos no início deste texto, tratase de tomar o plano de produção dos serviços e dos sujeitos, como plano estratégico, uma vez que se busca acompanhar um processo e não, apenas, representar uma dada realidade. 


\section{No rastro da premissa de indissociabilidade entre produção de serviços e produção de sujeitos}

O âmbito de inseparabilidade vai-nos permitir recuperar um eixo que a PNH estabeleceu como um dos seus pilares, focado no que se passa "em meio aos processos de trabalho". O princípio, nesse caso, seria o de contribuir para provocar a mobilização dos trabalhadores da Saúde em torno de análises e intervenções em seus processos locais de trabalho. Aqui a indissociabilidade deve ser perseguida na perspectiva de um trabalho em Saúde que se deseja ampliado e articulado em uma tríplice direção: produção de serviços, produção-sustentação da organização e produção de sujeitos (Campos, 2003). Em seu escopo, a PNH assume convocar os trabalhadores a olharem para seus processos de trabalho, analisando-os como um processo histórico, instituído por quem os compõe (trabalhadores, gestores e usuários). Logo, trata-se de um processo que pode ser modificado a partir da mobilização desses mesmos atores. Mobilização que traria em si a perspectiva de um protagonismo, (re)invenção do trabalho, produzindo serviços e produzindo-se, reinventando-se como sujeitos (Santos Filho, Barros, 2007).

A operacionalização desse princípio tem sido um desafio e vamos nos deter um pouco mais nessa questão, dialogando com alguns referenciais que ajudam a marcar a especificidade dessa intervenção.

Por condições de trabalho, compreendemos uma estrutura-organização mais ampla, destacando o que tem sido apontado como precarização do trabalho em saúde, desde as questões relacionadas com os vínculos trabalhistas até a degradação dos ambientes e processos em sua dimensão cotidiana, na rotina do trabalho. As reações locais mais visíveis em meio a essas condições aparecem como imobilização dos trabalhadores, permeadas por descrença, apatia, raiva, sofrimento patogênico, dor, desprazer, adoecimento.

Aqui queremos enfatizar uma contradição que, frequentemente, é presenciada no cotidiano dos serviços de saúde: ao mesmo tempo em que se propõem e se exigem mudanças, incluindo um discurso de fomento à autonomia e ao protagonismo dos trabalhadores em suas equipes, tenta-se, muitas vezes, restringir os espaços concretos de exercício de autonomia e protagonismo. Um desses "espaços concretos" é o âmbito de planejamento e avaliação local, de definição e validação de metas nos processos de trabalho, que deveria ser explorado de forma coletiva, participativa, na realidade local.

Outra situação que nos interessa ressaltar é a prerrogativa do "trabalho em equipe", em muitas ocasiões, tornando-se não um modo de "conexão" - de saberes, poderes e afetos (Campos, 2006, 2000) -, mas como um "fardo" vivido pelos trabalhadores, uma vez que a compreensão de "trabalho em equipe" é frágil e a constituição de equipes multiprofissionais não superou a fragmentação manifestada nas ações cotidianas dos serviços. Ela se mantém presente na dissociação dos procedimentos e tarefas de cada profissão, bem como na relação entre os trabalhadores de diferentes formações (Gomes et al., 2005). Isto é, não se mobilizam estratégias, a partir de uma perspectiva formativa, necessárias para se reinventar o trabalho, reinventando-se como trabalhadores articulados em equipes de trabalho, superando-se as cisões produzidas e mantidas pelas relações de saber-poder e pelas assimetrias entre as corporações profissionais. Vale enfatizar que o estilo de gestão local é uma das variáveis que mais contribuem nesse contexto.

No âmbito das práticas na $\mathrm{PNH}$, o desafio que se coloca, e que não é tomado como problema senso estrito, é a construção de um caminho metodológico que considera os enormes e reconhecidos avanços na organização dos serviços e as situações comuns no dia-a-dia. E aí, em nosso entendimento, está o desafio do apoio institucional nesse campo, uma vez que a intervenção é disparada a partir de uma postura metodológica de inclusão das diferentes variáveis que compõem as situações-problema, sem propor soluções para as situações adversas, nem "promessa de solução". Também não se trata de acolher problemas e queixas em uma perspectiva fatalista (como se condicionados e imutáveis em um dado ambiente que os determinam), muito menos pactuar com a usual percepção dos trabalhadores de que tal situação se deve a uma culpa exclusiva do outro, num contexto de culpabilização e vitimização.

No rastro dessa premissa, a direção de intervenção que nos parece afinada com o que estamos indicando é a de provocar "efeito nos grupos", incitando e apoiando a análise das situações vividas, perseguindo a alteração nos posicionamentos e atitudes diante dos fatos. Tomando esse eixo 


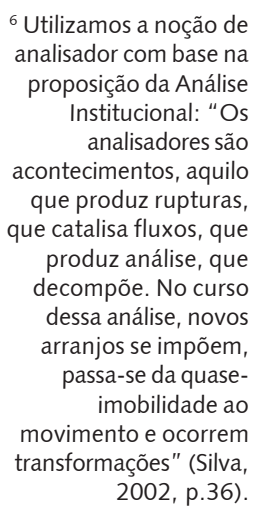

metodológico como um dos princípios constitutivos da $\mathrm{PNH}$, consideramos a adversidade e a própria posição dos sujeitos-trabalhadores como um analisador ${ }^{6}$ da gestão, que questiona o que está instituído e aponta para seu processo de constituição, sempre histórico. Assim, indagamos: com qual concepção de gestão se opera nesse caminho metodológico?

\section{Uma concepção de trabalho e de gestão: um caminho metodológico ou modos de fazer o apoio institucional}

Na direção proposta neste texto, a partir do diálogo com a PNH, ainda concebemos como relevante tratar a temática tomando uma concepção de trabalho e gestão que se abre nas seguintes vertentes: a) compreensão de que o trabalho é produção-invenção de serviços, de produtos, de si mesmo e do mundo (Schwartz, 2007) e de que, no processo de trabalho, a conexão construída é a das relações entre os atores que habitam os serviços (trabalhadores entre si e com gestores e usuários); b) compreensão de que o trabalho em saúde é um espaço por excelência dessa produção de serviços e de sujeitos (autonomia, protagonismo (Campos, 2006, 2003, 2000); c) compreensão de que o trabalho é produção de saber, processo de formação permanente, e que essa formação se efetiva na vivência das situações concretas de trabalho, "tornando-se competente" para enfrentar as demandas, criando estratégias para isso (inclusive aprendendo a trabalhar em equipe).

Zarifian (2001) compreende competência como atitudes, posições, ações e aprendizados que se constituem no confronto dos sujeitos com o que se apresenta nas situações de trabalho que vivenciam. O autor entende que " [...] uma das características mais interessantes e inovadoras da lógica competência reside, justamente, no fato de ela associar responsabilidade pessoal e corresponsabilidade, [relacionando a postura de] assumir responsabilidade" à perspectiva de autonomia (Zarifian apud Santos Filho, 2008, p.25).

Nesse sentido, pode-se correlacionar essa visão de competência com o que se deseja com a PNH, que é o aumento de autonomia e protagonismo dos sujeitos (Brasil, 2006), aumento da capacidade de análise e de intervenção dos sujeitos no contexto em que se encontram e vivem (Campos, 2006, 2003, 2000). Essa competência, portanto, não se refere a um indivíduo ou a uma qualidade inata a esse indivíduo; ela sempre nos remete ao coletivo de trabalho e é desenvolvida no encontro entre os sujeitos. É essa vivência, exercício da competência, com assunção de responsabilidade para o enfrentamento de uma situação, que equivale à atitude protagônica, autônoma, emancipatória.

Com esse fio condutor, compreende-se o espaço de trabalho como coconstruído pelos atores que estão em cena, e cada um é gestor de seu próprio fazer (Schwartz, 2000), tendo em conta que toda atividade pressupõe negociações e debates de normas para ser realizada. Logo, é sempre preciso gerir as infidelidades que o meio apresenta, pois todos que trabalham o fazem imprimindo sua marca (suas regulações) na medida em que vão fazendo-aprendendo e aprendendo-fazendo.

O processo de trabalho local, assim, não se resume ao que se materializa em produtos ou ao que é visível, mas também, como nos indica Clot (2006, p.116), abrange " [...] aquilo que não se faz, aquilo que não se pode fazer, aquilo que se busca fazer sem conseguir - os fracassos -, aquilo que se teria querido ou podido fazer, aquilo que se pensa ou que se sonha poder fazer alhures [...]" e, ainda, o "[...] que se faz para não fazer aquilo que se tem a fazer ou ainda aquilo que se faz sem querer fazer" (Clot, 2006, p.116). 
A atividade de trabalho é sempre marcada pela relação dramática entre autonomia e heteronomia. Trabalhamos sempre em meio a negociações, escolhas e arbitragens, nem sempre conscientes, que consideram o tipo de inserção de cada um e de todos que compartilham aquele meio de trabalho, mas, também, as políticas de saúde, os valores e as práticas de saúde instituídos, as relações de forças e de poderes presentes em cada situação de trabalho. Enfim, todos nós somos corresponsáveis pela gestão das situações de trabalho e temos o potencial de ajudar a transformá-las ou mantê-las como estão.

Consideramos, então, que a direção proposta para o apoio institucional na PNH é de intervir no sentido de ajudar a compreender que a desestabilização faz parte dos processos de trabalho e que o caminho é a mobilização para provocar outras e novas desestabilizações. Ou seja, compreender que, ao contrário de se conceber idealmente os processos de trabalho como "equilíbrios esperados", é preciso analisar e gerir os desequilíbrios. Esses desequilíbrios compõem o viver, daí a importância de entendêlos como potentes, quando temos como meta a produção de coletivos fortes, que podem acionar modos de trabalhar que afirmam a invenção própria dos vivos. Portanto, muito importa aqui a concepção de Humano e Humanismo, que indicamos no início deste texto, pois as desestabilizações serão provocadas e perseguidas, ou negadas, dependendo do esforço coletivo (corresponsabilização) na direção do que se tiver compreendendo e desejando como "humanização do serviço", num dado momento histórico.

Reafirmamos, a partir da $\mathrm{PNH}$, que os processos de trabalho estão inseridos em contextos "multivetorializados". Esse referencial é tomado como princípio para operarmos com "rodas" no cotidiano dos serviços - onde os trabalhadores se encontram para levantar problemas vividos, suas dores e "impossibilidades", com dificuldades de tratar as situações -, a partir de um método de inclusão (dos problemas-conflito e de todos os sujeitos; inclusão dos jeitos de trabalhar, de se relacionar e de viver). Ou seja, partir do concreto da experiência, das variabilidades e imprevisibilidades que se expressam, e tecer processos de trabalho, partir do saber da experiência que será problematizado.

Esse é o desafio que a PNH julga necessário ser incluído como matéria do trabalho, e é com essa matéria que nos propomos operar. Isto é não neutralizar os movimentos que emergem nos cotidianos de trabalho para começarmos a trabalhar, mas, sim, lidar com tudo isso, esperando transformações que alterem posicionamentos, que produzam outras formas de subjetividade e outros modos de subjetivação. A produção de saúde não está desarticulada da produção de sujeitos. Aqui há uma especificidade do apoio institucional/PNH (Brasil, 2006).

As estratégias metodológicas utilizadas primam por situar essa discussão no âmbito da gestão: tanto no sentido de como compreendemos a inserção dos sujeitos no trabalho (em que toda atividade de trabalho os mobiliza para diferentes níveis de gestão dos seus fazeres e saberes), mas também no sentido da gestão do processo de trabalho como desafio coletivo, como cogestão. O que essa "escolhadireção" traz de desafio? O de deslocar a discussão de "precarização", "insatisfação", "desgaste" e "adoecimento" no trabalho para o campo da análise coletiva do próprio trabalho. Isso significa deslocar ou superar o polo que tradicionalmente abriga essa discussão, reduzindo-a à esfera de "tratamento" (dos casos, dos problemas, dos doentes, dos absenteísmos, dos afastados etc.) e de "higienização" dos ambientes. Portanto, as mudanças que se desejam efetuar são tratadas no/ e a partir dos processos de gestão em curso.

A função de apoio institucional é, então, atravessada por uma provocação do exercício coletivo de regulação, nos moldes em que compreendemos essa lógica, que permite ajustar o previsto (normas, regras, metas etc.) às necessidades e jeitos dos sujeitos, com interesses, demandas, a partir de uma potência de invenção própria do viver (Santos Filho, 2008). E é nesse ato de ajuste que a PNH vislumbra uma emancipação. É por aí que podemos indicar, de forma mais concreta, o protagonismo e a autonomia na organização e reinvenção de si, das equipes e da prestação de serviços.

\section{Foco no "processo de trabalho humanizado": necessária inclusão dos usuários e dos trabalhadores/gestores}

Frequentemente podemos presenciar, nos serviços de Saúde, algumas situações que se expressam a partir da fragmentação das ações e sensação de isolamento-solidão no trabalho. Tais situações indicam a 
dificuldade de se efetivar o trabalho em equipe (Santos Filho, 2007a). A fragmentação do trabalho dá-se em meio a uma contradição que se expressa no embate entre novos modelos de atenção-gestão, que pressupõem processos de trabalho pautados no diálogo, e uma cultura da comunicação vertical e estilo de gestão que não fomenta momentos para comunicação-análise do fazer, com isso dificultando também uma inovação no âmbito da atenção ao usuário.

Assim, pautar uma comunicação lateralizada como um importante campo no debate sobre a humanização dos serviços de Saúde, como um componente indispensável para a afirmação da indissociabilidade atenção-gestão, parece-nos importante. Nesse sentido, a organização do processo de trabalho precisa ser pensada sempre como processo dialógico e polifônico, em que as múltiplas vozes e olhares estão em debate e negociação.

Então, as propostas da PNH, ao serem tomadas aqui como desafios, são postas em análise. Em que medida se tem dado conta dessas intervenções? Quais pistas nos ajudam a avaliar as repercussões desse modo de trabalhar? Tem-se cuidado para dimensionar o alcance dessas intervenções? De que forma? Com que referencial e com que instrumental? (Santos Filho, 2007b).

Tais questões, certamente, convocam a construir caminhos que nos ajudam a ampliar o debate sobre a indissociabilidade entre atenção e gestão, o modo de fazer apoio institucional proposto pela PNH e as estratégias avaliativas que podem nos ajudar a dimensionar o trabalho de apoio institucional ofertado.

A indissociabilidade entre a produção de serviços e a produção de sujeitos leva a afirmar: a aposta na inclusão dos diferentes sujeitos e na análise e gestão coletiva dos processos de trabalho é uma estratégia importante para a produção de desestabilizações produtivas e práticas de humanização dos serviços de Saúde que tomam os processos de trabalho como foco.

Entendemos que as práticas nomeadas humanizadas em saúde, perdem sua força disruptora, ou seja, perdem a força de produzir mudanças significativas nos serviços de Saúde na direção dos princípios do SUS, ao serem reduzidas a ações desarticuladas que não colocam em análise os processos de trabalho. A PNH, por meio dos seus dispositivos, parece-nos uma estratégia que se tem constituído como uma forte aliada, quando temos como princípio a ampliação e afirmação do SUS que dá certo.

\section{Colaboradores}

Os autores trabalharam juntos em todas as etapas de produção do manuscrito.

\section{Referências}

BARROS, M.E.B. et al. A experiência do programa de formação em saúde e trabalho em um hospital público com serviço de urgência. In: SANTOS FILHO, S.B.; BARROS, M.E.B. (Orgs.). Trabalhador da saúde: muito prazer! Protagonismo do trabalhador na gestão do trabalho em saúde. ljuí: Ed. Unijuí, 2007. p.185-202.

BARROS, M.E.B.; BENEVIDES DE BARROS, R. Da dor ao prazer no trabalho. In: SANTOS FILHO, S.B; BARROS, M.E.B. (Orgs.). Trabalhador da saúde: muito prazer! Protagonismo do trabalhador na gestão do trabalho em saúde. Ijuí: Ed. Unijuí, 2007. p.61-71.

BARROS, M.E.B.; MORI, M.E.; BASTOS, S.S. O desafio da política nacional de humanização nos processos de trabalho: o instrumento Programa de Formação em Saúde e Trabalho. Cad. Saude Colet., v.14, n.1, p.31-48, 2006.

BARROS, M.E.B.; SANTOS FILHO, S. (Orgs.). Trabalhador da saúde: muito prazer! Protagonismo dos trabalhadores na gestão do trabalho em saúde. Ijuí: Ed. Unijuí, 2007.

BENEVIDES, R.; PASSOS, E. Humanização na saúde: um novo modismo? Interface Comunic., Saúde, Educ., v.9, n.17, p.389-94, 2005. 
BRASIL. Ministério da Saúde. Secretaria de Atenção à Saúde. Núcleo Técnico da Política Nacional de Humanização. HumanizaSUS: documento base para gestores e trabalhadores do SUS. Brasília: Ministério da Saúde, 2006.

Secretaria-Executiva. Núcleo Técnico da Política Nacional de Humanização.

HumanizaSUS: Política Nacional de Humanização: a humanização como eixo norteador das práticas de atenção e gestão em todas as instâncias do SUS. Brasília: Ministério da Saúde, 2004.

CAMPOS, G.W.S. Apresentação. In: SANTOS FILHO, S.B.; BARROS, M.E.B. (Orgs.). Trabalhador da saúde: muito prazer! Protagonismo do trabalhador na gestão do trabalho em saúde. Ijuí: Ed. Unijuí, 2007. p.11-5.

Clínica e saúde coletiva compartilhadas: teoria paidéia e reformulação ampliada

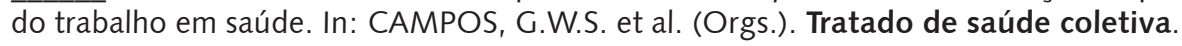
São Paulo: Hucitec, 2006. p.53-92.

Saúde Paidéia. São Paulo: Hucitec, 2003.

Um método para análise e co-gestão de coletivos. São Paulo: Hucitec, 2000.

O anti-Taylor: sobre a invenção de um método para co-governar instituições de saúde produzindo liberdade e compromisso. Cad. Saude Publica, v.14, n.4, p.863-70, 1998.

Subjetividade e administração de pessoal: considerações sobre modos de gerenciar o trabalho em equipes e saúde. In: MEHRY E.E.; ONOCKO, R. (Orgs.). Agir em saúde: um desafio para o público. São Paulo: Hucitec, 1997. p.229-66.

CLOT, Y. A função psicológica do trabalho. Petrópolis: Vozes, 2006.

FOUCAULT, M. Sobre a história da sexualidade. In: Microfísica do poder. Rio de Janeiro: Graal, 1999, p.244-76.

GOMES, R.S. et al. A orquestração do trabalho em saúde: um debate sobre a fragmentação das equipes. In: PINHEIRO, R.; MATTOS, R.A. (Orgs.). Construção social da demanda: direito à saúde, trabalho em equipe, participação e espaços públicos. Rio de Janeiro: IMS-UERJ, 2005. p.105-16.

HECKERT, A.L.C.; NEVES, C.A.B. Modos de formar e modos de intervir: quando a formação se faz potência de produção de coletivo. In: PINHEIRO, R.; MATTOS, R.A.; BARROS, M.E.B. (Orgs.). Trabalho em equipe sob o eixo da integralidade: valores, saberes e práticas. Rio de Janeiro: IMS/UERJ/Cepesc/Abrasco, 2007. p.145-60.

PASSOS, E. Proposta de apresentação dos níveis de composição da PNH. Rio de Janeiro, 2006. (Mimeogr.).

SANTOS FILHO, S.B. Construindo um método de acompanhamento avaliativo e avaliando processos de formação: em foco o curso de humanização da atenção e gestão em saúde do Mato Grosso. Relatório de Consultoria apresentado para o Ministério da Saúde. Brasília, 2008.

Dando visibilidade à voz dos trabalhadores: possíveis pontos para uma pauta de valorização? In: SANTOS FILHO, S.B.; BARROS, M.E.B. (Orgs.). Trabalhador da saúde: muito prazer! Protagonismo dos trabalhadores na gestão do trabalho em saúde. ljuí: Ed. Unijuí, 2007a. p.61-71.

Perspectivas da avaliação na Política Nacional de Humanização: aspectos conceituais e metodológicos. Cienc. Saude Colet., v.12, n.4, p.999-1010, 2007b.

SANTOS FILHO, S.B.; BARROS, M.E.B. A base político-metodológica em que se assenta um novo dispositivo de análise e intervenção no trabalho em saúde. In:

(Orgs.). Trabalhador da saúde: muito prazer! Protagonismo dos trabalhadores na gestão do trabalho em saúde. Ijuí: Ed. Unijuí, 2007. p.123-42. 
SCHWARTZ, Y.; DURRIVE, L. (Orgs.) Trabalho e ergologia: conversas sobre a atividade humana. Niterói: EdUFF, 2007.

. Travail et gestion: niveaux, critéres, instances. Rev. Perform. Techn. (Paris) n. hors-série, p.10-20, 2000.

SILVA, C.O. Vida de hospital: a produção de uma metodologia para o

desenvolvimento da saúde do profissional de saúde. 2002. Tese (Doutorado) - Escola Nacional de Saúde Pública, Fundação Oswaldo Cruz, Rio de Janeiro. 2002.

ZARIFIAN, P. Objetivo competência: por uma nova lógica. São Paulo: Atlas, 2001.

SANTOS FILHO, S.B.; BARROS, M.E.B.; GOMES, R.S. La Política Nacional de Humanización como política que se hace en el proceso de trabajo en salud. Interface - Comunic., Saude, Educ., v.13, supl.1, p.603-13, 2009.

El presente artículo tiene como objetivo hacer un ejercicio analítico del modo de hacer de la Política Nacional de Humanización, sobre la función apoyo institucional, con base en diferentes dispositivos, directrices y principios. El texto está dividido en tres partes. En la primera, trae reflexiones acerca de la concepción de humano y del humanismo que fundamenta los análisis. La segunda busca ampliar el debate sobre la inseparabilidad entre atención y gestión y el modo de hacer apoyo institucional. La tercera plantea la noción de inseparabilidad entre la producción de servicios y la producción de sujetos y encamina la discusión de estas tres partes que se desdoblan en otros planos de análisis. Resalta en todo el texto la apuesta en la inclusión de los diferentes sujetos y en el análisis y gestión colectiva de los procesos de trabajo como estrategia para crear desestabilizaciones productivas y prácticas de humanización de los servicios de salud.

Palabras clave: Humanización de la atención. Apoyo institucional. Co-gestión. Análisis colectiva de los procesos de trabajo. Políticas públicas. 